\title{
1 Self-healing antimicrobial polymer coating with 2 efficacy in the presence of organic matter
}

3 Luis J. Bastarrachea, Julie M. Goddard ${ }^{*}$

$4 \quad *$ Corresponding Author

5 goddard@umass.edu

6 Department of Food Science

7 University of Massachusetts

8102 Holdsworth Way

9 Amherst, Massachusetts

10 United States

11 Phone: (413) 545-2275. Fax: (413) 545-1262

${ }^{1}$ Present Address: goddard@,cornell.edu, Department of Food Science, Cornell University, Ithaca, NY 


\section{ABSTRACT}

14 A method to prepare a self-healing, antimicrobial polymer coating that retains efficacy against

15 Escherichia coli $\mathrm{O} 157: \mathrm{H} 7$ in the presence of organic matter is reported. A coating composed of

16 branched polyethyleneimine (PEI) and styrene maleic anhydride copolymer (SMA) was applied

17 to a maleic anhydride functionalized polypropylene support. The chemistry of the polymer

18 coating was designed to impart hydrophobicity due to the styrene subunits, intrinsic

19 antimicrobial character ( $>99.9 \%$ reduction) from the cationic primary amine groups, and

20 enhanced antimicrobial character ( $>99.99 \%$ reduction) after chlorination of $N$-halamine forming

21 groups. Antimicrobial effectiveness was demonstrated under conditions of increasing organic

22 load. Up to $500 \mathrm{ppm}$ horse serum, chlorinated coatings retained full antimicrobial character $(>$

$2399.99 \%$ reduction). Even at 50,000 ppm of horse serum, the coating provided $\sim 90 \%$ reduction as

24 prepared, and between $\sim 75 \%$ and $\sim 80 \%$ reduction in the form of $N$-halamines. Microscopy

25 confirmed no evidence of bacterial adhesion on the coating surface. Finally, the coating

26 exhibited self-healing properties after exposure to acid and alkaline solutions and restoration by

27 heat, as confirmed through spectroscopy from the rebuilding of characteristic chemical bonds.

28 Such robust antimicrobial polymer coatings with efficacy under conditions of increasing organic

29 load may support reducing microbial cross-contamination in food and biomedical industries.

\section{KEYWORDS}

32 Antimicrobial material, $N$-halamines, polycations, self-healing material, antimicrobial coating,

33 microbial cross-contamination. 


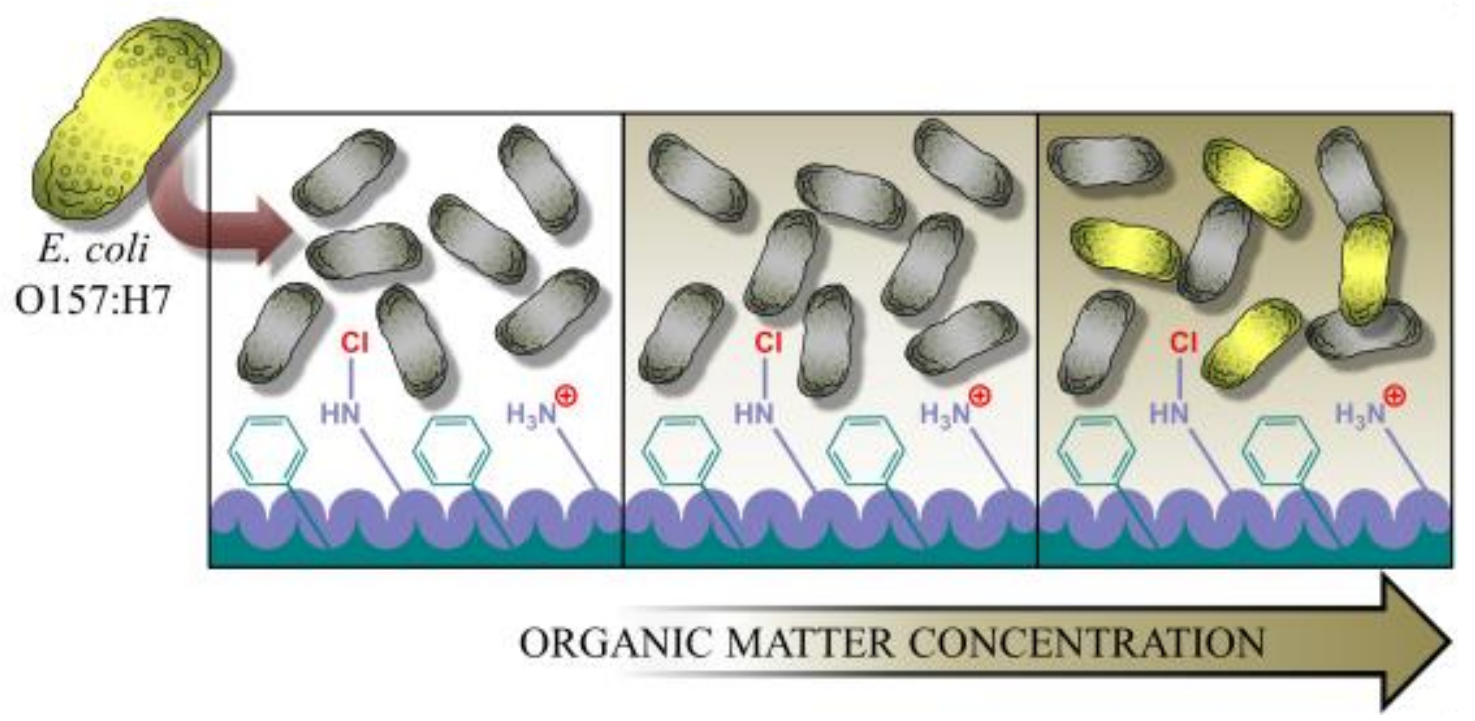

37 


\section{INTRODUCTION}

39 Microbial contamination of surfaces and materials remains a problem in the food and biomedical

40 industries both to public health and as a financial burden to the government. It is estimated that

41 every year in The United States of America approximately 48 million people get sick from

42 foodborne diseases [1]. In addition, in 2011 there were approximately 722,000 health-care

43 related infections [2]. According to the Food and Drug Administration of The United States of

44 America, contaminated utensils and surfaces are among the top 5 risk factors for foodborne

45 outbreaks [3]. To decrease the risk of microbial infections, the food and biomedical industries

46 employ mainly physical and chemical sanitization methods that involve the use of heat (in the

47 form of steam, irradiation, etc.) or disinfectants like quaternary ammonium compounds or

48 hydrogen peroxide [4]. However, such sanitization methods suffer limitations such as reduced

49 efficacy in the presence of organic matter (almost unavoidable in food processing equipment and

50 medical utensils), degradation of surfaces with repeat sanitization (resulting in a rough

51 morphology more supportive of biofilm establishment), and development of microbial resistance

52 [5]. The development of antimicrobial materials and coatings therefore remains a promising

53 opportunity to support cleaning and sanitization protocols in preventing microbial contamination

54 in the food and biomedical industries.

One strategy to prepare antimicrobial materials has been the application of thin coatings

56 with antimicrobial character onto the surface of commonly used materials [5-7]. One of the main

57 advantages of this concept is to keep the bulk properties of the coated materials intact [8].

58 Antimicrobial character can be imparted by embedding antimicrobial agents throughout the

59 coating matrix [9], however this strategy requires leaching of the antimicrobial to be effective,

60 resulting in eventual loss in antimicrobial activity and the potential for development of resistant 
61 organisms [10-12]. Integration of antimicrobial moieties (e.g. $\mathrm{N}$-halamines, cationic) into

62 polymer structures seeks to overcome these limitations. $N$-halamines are a class of

63 antimicrobials in which nitrogen atoms bond with halogens (most commonly chlorine), exert

64 antimicrobial character by releasing the halogen, and are able to regenerate antimicrobial

65 character by repeated exposure to the halogen source for many cycles of disinfection. This

66 regenerative property constitutes the main feature of $N$-halamines, making them able to be reused

67 constantly [13-16]. The mechanisms involved in the microbial inactivation caused by $\mathrm{N}$ -

68 halamines have not been confirmed, but are believed to involve damage of genetic information,

69 cell membrane disruption, and denaturation of vital biomolecules [9, 17]. $N$-halamines have

70 shown efficacy against several types of microorganisms in a number of published studies, but

71 have limited efficacy in the presence of organic matter and may not present sufficient durability

72 due to the necessary repeated exposure to a halogen source, as well as other deteriorating agents

73 (e.g. light, heat, $\mathrm{pH}$ extremes) [9, 18-21]. Cationic polymers are another classification of

74 antimicrobials believed to inactivate microorganisms by membrane disruption [9, 22, 23]. Like

$75 \mathrm{~N}$-halamines, their effectiveness has been demonstrated against several microorganisms [24-27];

76 however, given their charged nature, they can be prone to fouling [24, 28-30], and have been

77 reported to lose biocidal efficacy in the presence of organic matter [9, 31]. Prior publications

78 indicate that integration of dual biocidal character in a coating can improve antimicrobial

79 efficacy without the need for frequent rechlorination [20,32-34], yet stability of the coatings and

80 preservation of antimicrobial efficacy in the presence of organic matter remains a significant 81 challenge [9].

82 We report a method for coat-cure preparation of a polymer coating which exhibits 83 antimicrobial efficacy due to integration of both $N$-halamine and cationic moieties within the 
84 polymer structure. The coating did not promote microbial adhesion, despite presence of

85 antimicrobial polycations. Preparation of the coating by assembly of polymers which generate

86 reactive chemical species (e.g. amine, carboxylic acids, carbonyls, anhydride) after damage

87 resulted in a coating with the molecular mobility and thermodynamic reversibility necessary to

88 enable self-healing through application of heat [21,35-38]. The antimicrobial coating was

89 applied to a reactive blend composed of polypropylene and polypropylene-graft-maleic

90 anhydride, and its effectiveness was demonstrated under increasing levels of organic matter

91 against the pathogen Escherichia coli $\mathrm{O} 157: \mathrm{H} 7$.

\section{$92 \quad 2$ Materials and Methods}

93 Polypropylene (PP, isotactic) and styrene maleic anhydride copolymer (SMA, $6 \mathrm{kDa}$ ) were

94 purchased from Scientific Polymer Products (Ontario, NY, USA). Polypropylene-graft-maleic

95 anhydride (PP-g-MA, $9.1 \mathrm{kDa}$ ), branched polyethyleneimine (PEI, $25 \mathrm{kDa})$, 4-(2-

96 hydroxyethyl)-1-piperazineethane-sulfonic acid (HEPES), and horse serum were purchased from

97 Sigma-Aldrich (St. Louis, MO, USA). The dye Orange (II) (Cert) (AO7), sodium hypochlorite

98 solution ( $5 \%$ chlorine), and reagent grade ethanol were purchased from Acros Organics (Fair

99 Lawn, NJ, USA). $N, N$-Diethyl-p-phenylenediamine (DPD) total chlorine reagent powder was

100 purchased from Hach Co. (Loveland, CO, USA). Tryptic soy agar (TSA), tryptic soy broth

101 (TSA) and neutralizing buffer (containing sodium thiosulfate to neutralize residual chlorine)

102 were purchased from Difco, Becton Dickinson (Sparks, MD, USA.)

\section{$103 \quad 2.1$ Preparation of antimicrobial coating}

104 Pellets of PP were cleaned under sonication first with isopropanol, then with acetone, and then 105 with deionized (DI) water (two cycles of $10 \mathrm{~min}$ for each solvent). Pellets of PP-g-MA were 
106 cleaned under sonication first with acetone and then with DI water (two cycles of 10 min for 107 each solvent). Cleaned pellets were left drying overnight under anhydrous calcium sulfate $(\mathrm{RH}<$ $10820 \%)$. Cleaned pellets of PP $(90 \% \mathrm{w} / \mathrm{w})$ and PP- $g$-MA $(10 \% \mathrm{w} / \mathrm{w})$ were blended in a Brabender 109 mixer model R.E.E.6. (50 mL capacity, Duisburg, Germany) at $190{ }^{\circ} \mathrm{C}$ and $60 \mathrm{rpm}$ for $5 \mathrm{~min}$. 110 Then, cooled pieces of the blend (PP/PP- $g$-MA) were hot-pressed at the same temperature with a 111 load force of $9000 \mathrm{lbs}$. to a final thickness of $0.24 \pm 0.03 \mathrm{~mm}$. The hot-pressed films were cut 112 into $2 \times 2 \mathrm{~cm}$ coupons, cleaned with acetone and DI water as described previously, and left 113 drying overnight under the same conditions.

114 The antimicrobial polymer coating was applied to pressed films of PP/PP-g-MA by sequential 115 application of PEI and SMA as illustrated in Figure 1. PEI and SMA were separately mixed with 116 acetone at concentrations of $0.06 \mathrm{~g} \mathrm{~mL}^{-1}$ and $0.04 \mathrm{~g} \mathrm{~mL}^{-1}$, respectively, and sonicated for $20 \mathrm{~min}$ 117 or until the polymers were completely dissolved. Aliquots of each polymer solution $(300 \mu \mathrm{L})$ 118 were spin coated onto PP/PP-g-MA coupons for $1 \mathrm{~min}$ at $3000 \mathrm{rpm}$ in the order: PEI, SMA, PEI. 119 Coated coupons were cured for $20 \mathrm{~min}$ at $165{ }^{\circ} \mathrm{C}$ to enable crosslinking between amines and 120 anhydride groups. Cured, coated coupons were labeled as PP-PEI-SMA-PEI. 


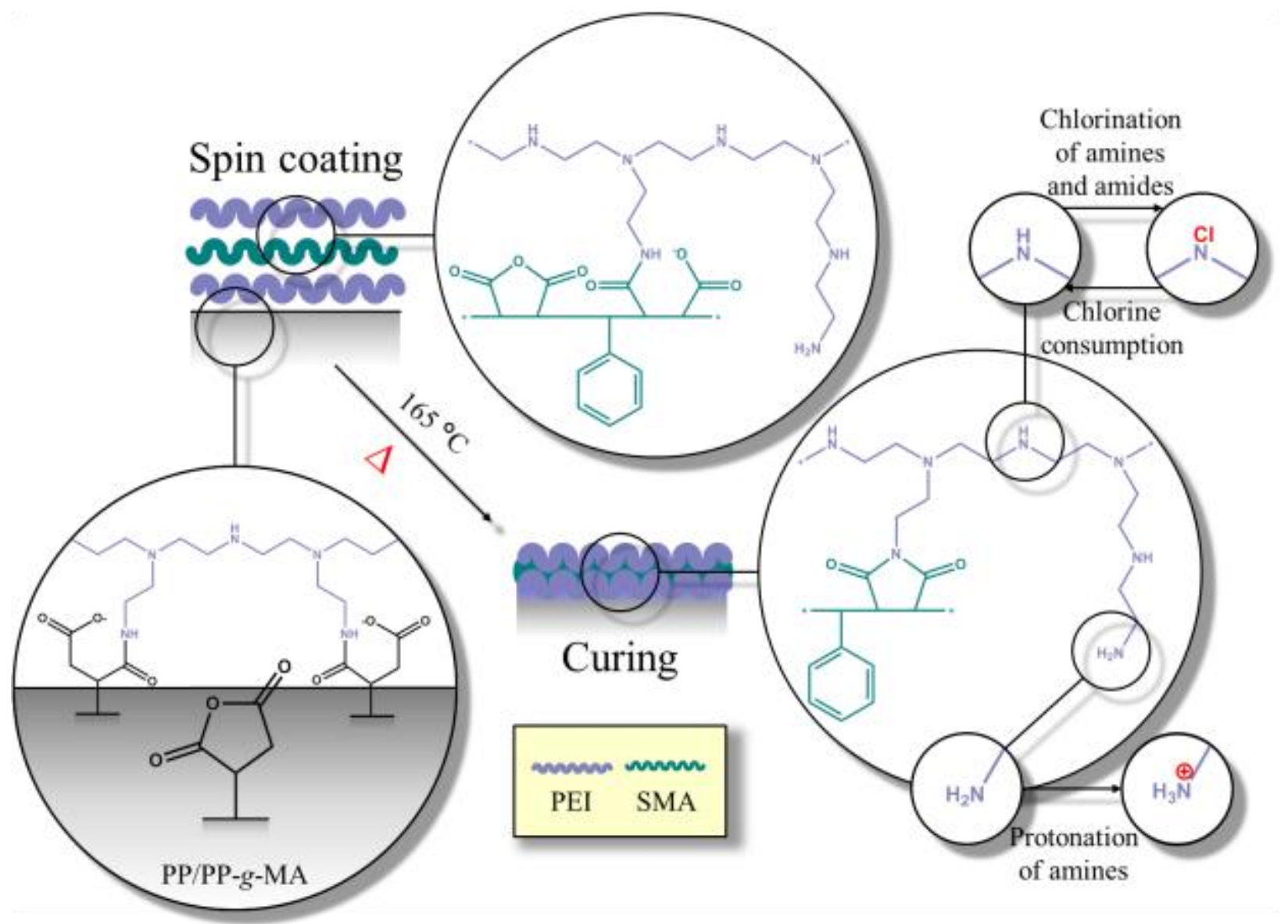

Figure 1. Preparation of the antimicrobial coating.

\subsection{Antimicrobial coating characterization}

2.2.1 Attenuated Total Reflectance Fourier Transform Infrared Spectroscopy (ATR-FTIR). At every step of the preparation of the antimicrobial coating, coupons were analyzed with an IRTracer-100 spectrometer (Shimadzu corp., Japan), equipped with a diamond ATR crystal

127 (penetration depth $\sim 2 \mu \mathrm{m}$ ). Multiple spots of coupons from each of at least 3 separately prepared 128 sets (3 replicates) were analyzed using Happ-Genzel apodization (32 scans per spot, with a 129 resolution of $4 \mathrm{~cm}^{-1}$ ). Obtained spectra were subjected to baseline correction and analyzed with 130 the software KnowItAll (Bio-Rad Laboratories, Philadelphia, PA, USA). Average spectra from 
131 each preparation step were selected and combined for comparison. After the self-healing studies

132 (explained below), coupons were analyzed under the same conditions.

133 2.2.2 Primary amine quantification. The Acid Orange 7 (AO7) assay [40] was employed to

134 determine the amount of primary amines on the surface of the antimicrobial coating. The $2 \times 2$

$135 \mathrm{~cm}$ PP-PEI-SMA-PEI coupons were cut into $1 \times 1 \mathrm{~cm}$ pieces and individually immersed in test

136 tubes containing $5 \mathrm{~mL}$ of a $1 \mathrm{mM}$ solution of $\mathrm{AO} 7$, adjusted with $\mathrm{HCl}$ to a $\mathrm{pH}$ of 3.0 , and shaken

137 for $3 \mathrm{~h}$. Then, coupons were rinsed with copious pH 3.0 DI water to desorb unbound dye,

138 immersed individually in test tubes containing $5 \mathrm{~mL}$ of $\mathrm{pH} 12$ DI water adjusted with $\mathrm{NaOH}$, and

139 shaken for $15 \mathrm{~min}$ to desorb bound dye. Absorbances were read at $455 \mathrm{~nm}$ and the primary amine

140 content was determined by comparison to a standard curve prepared with $\mathrm{pH} 12$ solutions

141 containing different concentrations of AO7. This evaluation was conducted with PP-PEI-SMA-

142 PEI coupons obtained from separately prepared sets $(3$ replicates, with at least two $1 \times 1 \mathrm{~cm}$

143 coupons per replicate). PP/PP-g-MA coupons were analyzed under the same conditions as

144 control.

$145 \quad 2.2 .3 \mathrm{~N}$-halamine quantification. $\mathrm{N}$-halamine forming groups were chlorinated by immersing

146 PP-PEI-SMA-PEI coupons $(1 \times 1 \mathrm{~cm}$ pieces $)$ individually in test tubes containing $1 \mathrm{~mL}$ of 200

$147 \mathrm{ppm}$ of chlorine prepared from sodium hypochlorite solution (5\% chlorine, confirmed through

148 iodometric titration [41]). To characterize chlorination kinetics, PP-PEI-SMA-PEI coupons were

149 removed from chlorine solution at different time points, rinsed with copious DI water, and

150 analyzed for $N$-halamine content using the colorimetric DPD assay [12, 20, 42, 43]. Briefly, 50

$151 \mu \mathrm{L}$ DPD reagent (prepared by dissolving individual packets of DPD total chlorine reagent in 1

$152 \mathrm{ml}$ DI water) was added to a test tube containing $2 \mathrm{~mL}$ of DI water and the PP-PEI-SMA-PEI

153 coupons, and shaken for $5 \mathrm{~min}$ for color generation. Absorbances were read at $512 \mathrm{~nm}$ and the $\mathrm{N}-$ 
154 halamine content determined by comparison to a standard curve of aqueous chlorine solution. To

155 determine the time to reach chlorine saturation, the exponential association model was used:

$156 \quad \mathrm{NH}=\mathrm{NH}_{\text {asympt }}\left(1-\mathrm{e}^{-K t}\right)$

157 where $\mathrm{NH}$ is the $\mathrm{N}$-halamine content $\left(\mathrm{nmol} \mathrm{cm}{ }^{-2}\right), \mathrm{NH}_{\text {asympt }}$ is the theoretical maximum amount of $158 \mathrm{~N}$-halamines reached at saturation, $K$ is the kinetic factor $\left(\mathrm{min}^{-1}\right)$, and $t$ is the time (min). $N$ 159 halamine values at the different time points were fitted with Equation 1 using GraphPad Prism 5 160 version 5.04 (GraphPad Software Inc., La Jolla, CA, USA). This evaluation was performed 3 161 times with at least 2 coupons for each time point prepared from separately prepared sets (3 162 replicates). As controls, PP/PP-g-MA and unchlorinated PP-PEI-SMA-PEI coupons were used.

163 2.2.4 Atomic Force Microscopy (AFM). Surface topographies of PP/PP-g-MA and PP-PEI164 SMA-PEI coupons were analyzed with a Dimension 3100 atomic force microscope (Digital 165 Instruments, Santa Barbara, CA, USA) with tapping mode using an uncoated Si N-type tip $\left(f_{0}=\right.$ $166200-400 \mathrm{kHz}$, Applied NanoStructures Inc., Mountain View, CA, USA). At least 3 167 measurements were taken, and mean square roughness $\left(R_{q}\right)$ values were obtained from the SPIP 168 6.0.6 software (Scanning Probe Image Processor, Image Metrology, Hørsholm, Denmark).

169 2.2.5 Water contact angle and surface $p K_{a}$. Advacing $\left(\theta_{\mathrm{A}}\right)$ and receding $\left(\theta_{\mathrm{R}}\right)$ water contact 170 angles were determined with a drop shape analyzer DSA100 (Krüss, Hamburg, Germany). 171 PP/PP- $g$-MA and PP-PEI-SMA-PEI coupons were cut into $1 \times 2 \mathrm{~cm}$ samples for analysis. At 172 least two spots were analyzed for each $1 \times 2 \mathrm{~cm}$ coupon by applying a $5 \mu \mathrm{L}$ drop of DI water at $17325 \mu \mathrm{L} \min ^{-1}$. Data were obtained with the DSA software version 1.91.0.2 (Krüss, Hamburg, 174 Germany). For the surface $\mathrm{p} K_{\mathrm{a}}$ determination, the static contact angle $\left(\theta_{\mathrm{S}}\right)$ at different $\mathrm{pH}$ levels 
175 was determined as follows [20,44-46]. Values of $\theta_{\mathrm{S}}$ were obtained by applying $5 \mu \mathrm{L}$ of $10 \mathrm{mM}$

176 HEPES, adjusted to $\mathrm{pH} 1-13$ by $\mathrm{HCl}$ and $\mathrm{NaOH}$ on PP/PP- $g$-MA and PP-PEI-SMA-PEI 177 coupons and measuring the contact angle after $15 \mathrm{~s}$ of application with the DSA software $(1 \times 2$

$178 \mathrm{~cm}$ coupons, at least 2 spots per coupon). At least one $1 \times 2 \mathrm{~cm}$ coupon from each of 3 separately 179 prepared sets was used for contact angle and $\mathrm{pK}_{\mathrm{a}}$ determinations (at least 3 replicates).

\subsection{Antimicrobial evaluations}

181 A loopful of frozen culture of Escherichia coli O157:H7 ATCC 43895 (kept at $-80{ }^{\circ} \mathrm{C}$ in $25 \%$

182 glycerol, provided by Dr. Lynne A. McLandsborough from the food science department at the 183 University of Massachusetts Amherst, USA) was inoculated onto TSA and incubated at $37{ }^{\circ} \mathrm{C}$ 184 for $24 \mathrm{~h}$. Then, an individual colony from the TSA plates was inoculated in $9 \mathrm{~mL}$ of TSB and 185 incubated for $14 \mathrm{~h}$ at the same temperature. A loopful of the overnight broth was inoculated onto 186 TSA and incubated at $37{ }^{\circ} \mathrm{C}$ for $24 \mathrm{~h}$. The resulting colonies on TSA were kept at refrigeration 187 temperature for no more than 3 weeks for use in preparing inocula as described below.

For the antimicrobial evaluations, a single colony of E. coli $\mathrm{O} 157: \mathrm{H} 7$ was inoculated in

$189 \mathrm{TSB}$ and incubated for $14 \mathrm{~h}$ at $37{ }^{\circ} \mathrm{C}$. A $1 \%$ dilution of the overnight culture was prepared in 190 fresh TSB and incubated at $37^{\circ} \mathrm{C}$ to mid-exponential phase. Finally, a $0.1 \%$ aqueous dilution of 191 the mid-exponential phase culture was prepared for a microbial load of $\sim 6 \log \left(\mathrm{CFU} \mathrm{mL}^{-1}\right)$. 192 Horse serum, previously heat inactivated at $56^{\circ} \mathrm{C}$ as suggested by the provider, was added to the 193 aqueous suspension at concentrations up to $50,000 \mathrm{ppm}$ to demonstrate the efficacy of the 194 antimicrobial material in the presence of organic matter [47]. For each treatment, four $1 \times 1 \mathrm{~cm}$ 195 coupons were put in contact with $1 \mathrm{~mL}$ of bacterial suspension and rotated $(60 \mathrm{rpm})$ for $2 \mathrm{~h}$ at 32 $196{ }^{\circ} \mathrm{C}[20,21,43]$. The initial $10 \%$ serial dilution was prepared with neutralizing buffer (containing 
197 sodium thiosulfate) to quench chlorine, and subsequent $10 \%$ serial dilutions were prepared with

$1980.9 \%$ saline water. To lower the limit of detection to $1 \log \left(\mathrm{CFU} \mathrm{mL} \mathrm{mL}^{-1}\right)$, the entire volume $(1 \mathrm{~mL})$

199 of the first dilution was plated onto 3 TSA plates ( $333 \mu \mathrm{L}$ per plate). TSA plates were incubated

200 for $48 \mathrm{~h}$ at $37{ }^{\circ} \mathrm{C}$, and colonies were counted thereafter with a plate reader Scan 500

201 (Interscience, Saint-Nonla-Brèteche, France). As negative controls, bacterial suspensions alone,

202 PP/PP-g-MA, and chlorinated PP/PP-g-MA (chlorinated for $1 \mathrm{~h}$ under the same scheme

203 explained before for the $N$-halamine quantification) were used. As a positive control, diluted

204 bleach was added to the bacterial suspensions to imitate the chlorine content given by the four 1

$205 \times 1 \mathrm{~cm}$ coupons of chlorinated PP-PEI-SMA-PEI. The other 2 treatments were PP-PEI-SMA-PEI

206 and chlorinated PP-PEI-SMA-PEI (coupons were chlorinated for $1 \mathrm{~h}$ under the scheme described

207 previously for the $N$-halamine quantification). The time for chlorination was chosen because this

208 was the time required to reach $N$-halamine saturation, as it will be explained below.

209 SEM was used to confirm lack of bacterial attachment on the antimicrobial coating. PP-

210 PEI-SMA-PEI coupons with 0 and $50000 \mathrm{ppm}$ horse serum, with or without chlorination were

211 evaluated. After the antimicrobial efficacy assay, coupons were rinsed 3 times with sterile DI

212 water and then immersed for $45 \mathrm{~s}$ in reagent grade ethanol to fix any bound bacteria [48]. Then,

213 coupons were sputter-coated with gold for $30 \mathrm{~s}$ under argon with a Cressington Sputter Coater

214108 Auto (Ted Pella, Inc., Redding, CA, USA). At least 10 images were acquired across each

215 coupon using a scanning electron microscope (JCM-6000 NeoScope, JEOL, Japan) at $10 \mathrm{kV}$.

\section{$216 \quad 2.4$ Self-healing evaluations}

217 PP-PEI-SMA-PEI coupons were characterized for stability against chemical degradation and 218 capacity for self-healing. Resistance of the coatings to degradation was tested using an 
219 adaptation of standard conditions in which coupons are submerged in either $5 \% \mathrm{HCl}$ or $4 \%$

$220 \mathrm{NaOH}$ with rotation at $20{ }^{\circ} \mathrm{C}$ for 10 hours [49-51]. After rinsing with copious DI water and

221 drying under filtered air, coupons were subjected to a self-healing treatment of heating at $140{ }^{\circ} \mathrm{C}$

222 for 20 min. Coupons were analyzed by SEM, ATR-FTIR, $N$-halamine content, and X-Ray

223 Photoelectron Spectroscopy (XPS) at each stage (as prepared, either $\mathrm{HCl}$ or $\mathrm{NaOH}$ treated, and

224 after self-healing at $140{ }^{\circ} \mathrm{C}$ ). For XPS analysis, at least 1 coupon from each of 3 separately

225 prepared sets (3 replicates) was analyzed at each stage with a Physical Electronics Quantum

2262000 (Physical Electronics, Chanhassen, MN, USA) at an angle of $45^{\circ}$ with $\mathrm{Al} \mathrm{K \alpha}$ excitation

227 (with a spot size of $100 \mu \mathrm{m}$ and penetration depth of $2.5-3.0 \mathrm{~nm}$ ). Survey scans were collected

228 at a pass energy of $187.85 \mathrm{eV}$ (step size of $1.6 \mathrm{eV}$ ), and high resolution scans of $\mathrm{O} 1 \mathrm{~s}$ and $\mathrm{N} 1 \mathrm{~s}$

229 were collected at a pass energy of $46.95 \mathrm{eV}$ (step size of $0.4 \mathrm{eV}$ ). Results were analyzed with the

230 software Multipak version 6.1A (Physical Electronics, Chanhassen, MN, USA), using the

231 Gaussian-Lorentzian model (90\% Gaussian).

\section{$232 \quad 2.5$ Statistical analysis}

233 When appropriate, significant differences between treatments were determined through analysis

234 of variance followed by Tukey's pairwise comparisons with a $95 \%$ confidence interval using the 235 software GraphPad Prism 5 version 5.04 (GraphPad Software Inc., La Jolla, CA, USA).

\section{RESULTS AND DISCUSSION}

\section{$237 \quad 3.1$ Antimicrobial coating characterization}

238 ATR-FTIR spectra of the polymers used to prepare PP/PP-g-MA solid supports (Figure 2, top)

239 revealed absorbance bands characteristic of anhydrides $\left(\mathrm{C}=\mathrm{O}\right.$ vibrations at $1850 \mathrm{~cm}^{-1}$ and 1780 
$240 \mathrm{~cm}^{-1}$ ), as well as the carbonyl band from carboxylic acids at $1740-1720 \mathrm{~cm}^{-1}$. It can be observed

241 that after blending, these absorbances become less pronounced. The bottom graph shows the

242 steps during the preparation of the antimicrobial coating: (A) PP/PP-g-MA, (B) application of

243 first layer of PEI, (C) application of the SMA layer, (D) application of the second layer of PEI,

244 and (E) curing. The band at $\sim 1550 \mathrm{~cm}^{-1}$ in spectrum B (characteristic of the $\mathrm{N}-\mathrm{H}$ bond in-plane

245 bend of secondary amides) suggests some initial binding between the primary amine groups of

246 PEI and the maleic anhydride groups on the surface of PP/PP-g-MA. Spectrum C shows the

247 characteristic bands of anhydrides at $1850 \mathrm{~cm}^{-1}$ and $1780 \mathrm{~cm}^{-1}$ from SMA. After the application

248 of the second layer of PEI (spectrum D), the disappearance of the bands at $1850 \mathrm{~cm}^{-1}$ and 1780

$249 \mathrm{~cm}^{-1}$ and the increment in the absorbance level at $\sim 1550 \mathrm{~cm}^{-1}$ suggests opening of all the maleic

250 anhydride rings of SMA and higher crosslinking (amide bond formation) between PEI and SMA.

251 Finally, a more pronounced absorbance at $\sim 1650 \mathrm{~cm}^{-1}$ (corresponding to the $\mathrm{C}=\mathrm{O}$ group of

252 amides and imides) suggests the ring-closing step brought by curing at $165{ }^{\circ} \mathrm{C}$ (Figure 1) [20, 253 52].

254

255 


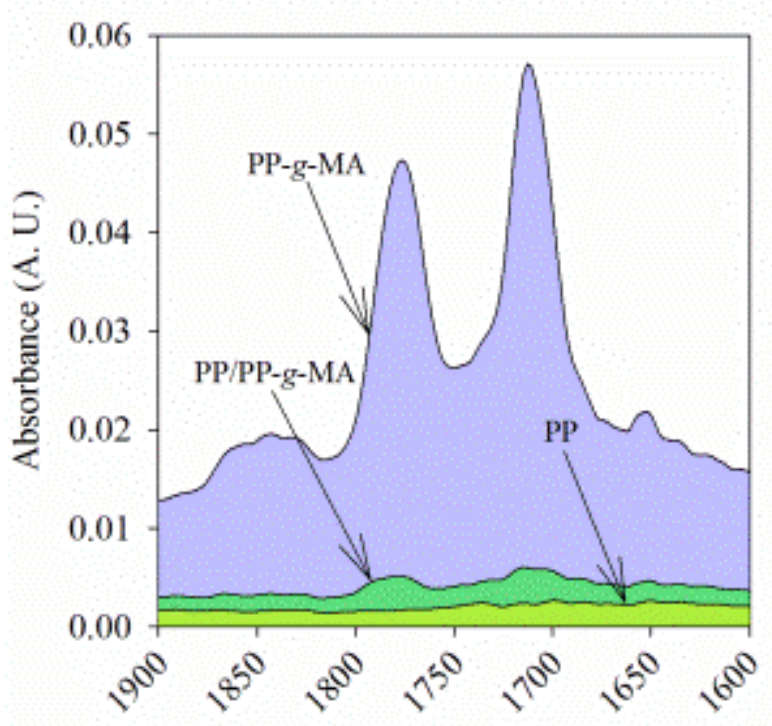

Wavenumbers $\left(\mathrm{cm}^{-1}\right)$

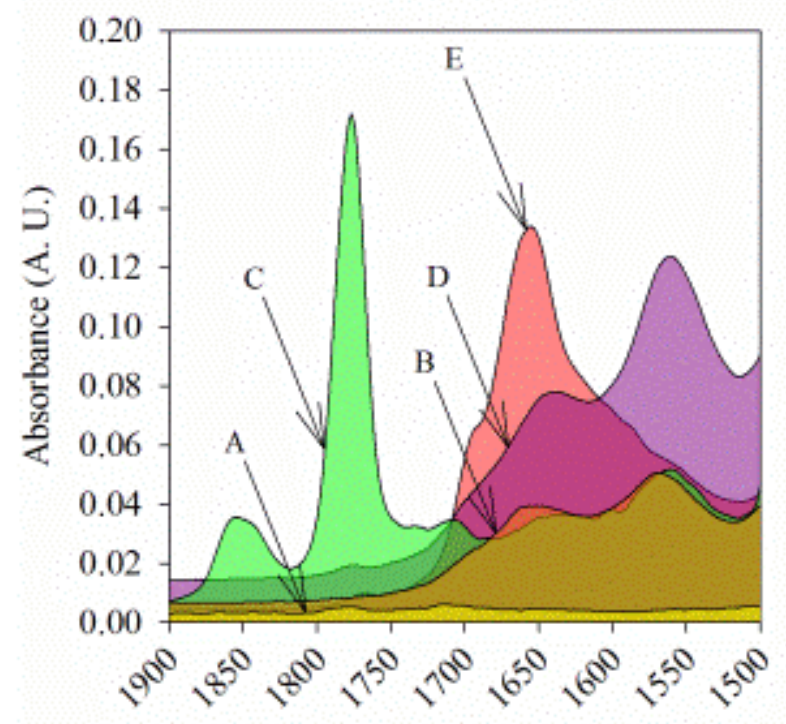

Wavenumbers $\left(\mathrm{cm}^{-1}\right)$

Figure 2. ATR-FTIR spectra of the raw materials to obtain PP/PP-g-MA (top) and the preparation steps of PP-PEI-SMA-PEI.

259 AO7 and DPD dye assays were used to quantify the primary amine and $N$-halamine content, 260 respectively, of PP-PEI-SMA-PEI. As expected, no measurable primary amines were detected on 261 the surface of PP/PP-g-MA, while PP-PEI-SMA-PEI coupons exhibited $334.2 \pm 33.0 \mathrm{nmol}$ 262 primary amines per $\mathrm{cm}^{2}$. Figure 3 shows the exponential association curve (Equation 1) 
263 illustrating the chlorination kinetics and chlorine holding capacity of PP-PEI-SMA-PEI. N-

264 halamine saturation was reached after $1 \mathrm{~h}$ of exposure to $200 \mathrm{ppm}$ of chlorine $\left(\mathrm{NH}_{\text {asympt }}=120.2\right.$

$\left.265 \pm 3.9 \mathrm{nmol} \mathrm{cm}{ }^{-2}, K=0.01 \pm 0.0 \mathrm{~min}^{-1}\right)$. No measurable chlorine was detected from PP/PP- $g$-MA

266 coupons that had been exposed to equivalent chlorination conditions (up to 120 min under 200

267 ppm of chlorine). These results support the findings of FTIR analysis which suggest that the

268 PEI-SMA-PEI coating introduced both cationic and $N$-halamine forming antimicrobial moieties.

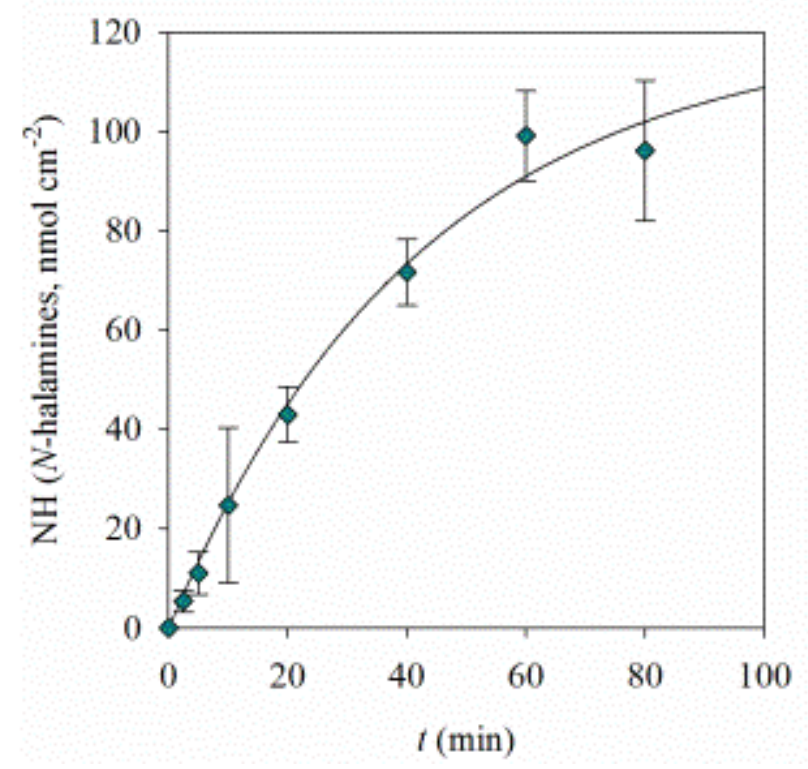

270

Figure 3. $N$-halamine (vertical axis, NH) quantification. Data fitted with Equation 1 (trend line, $\left.R^{2}=0.94 \pm 0.01\right)$.

Figure 4 shows the AFM images of PP/PP-g-MA (top) and PP-PEI-SMA-PEI (bottom).

273 The $R_{q}$ values of PP/PP-g-MA and PP-PEI-SMA-PEI were $6.9 \pm 3.3$ and $7.5 \pm 4.0 \mathrm{~nm}$,

274 respectively (not significantly different, $P>0.05$ ). As it can be observed, pores were found on

275 the surface of PP-PEI-SMA-PEI with a diameter of $\sim 100 \mathrm{~nm}$. The observed porosity may be a

276 result of evaporation of acetone used to apply the polymers, or of water produced during

277 condensation of maleic anhydrides with primary amines during cross-linking, as previously 
278 observed [20,53]. Thickness of the polymer coating was measured by applying a piece of kapton 279 tape to a section of the polypropylene solid support prior to coating. Kapton tape was then 280 removed to enable thickness quantification by optical profilometry. The reported coatings were $2813.0 \mu \mathrm{m}$ in thickness.
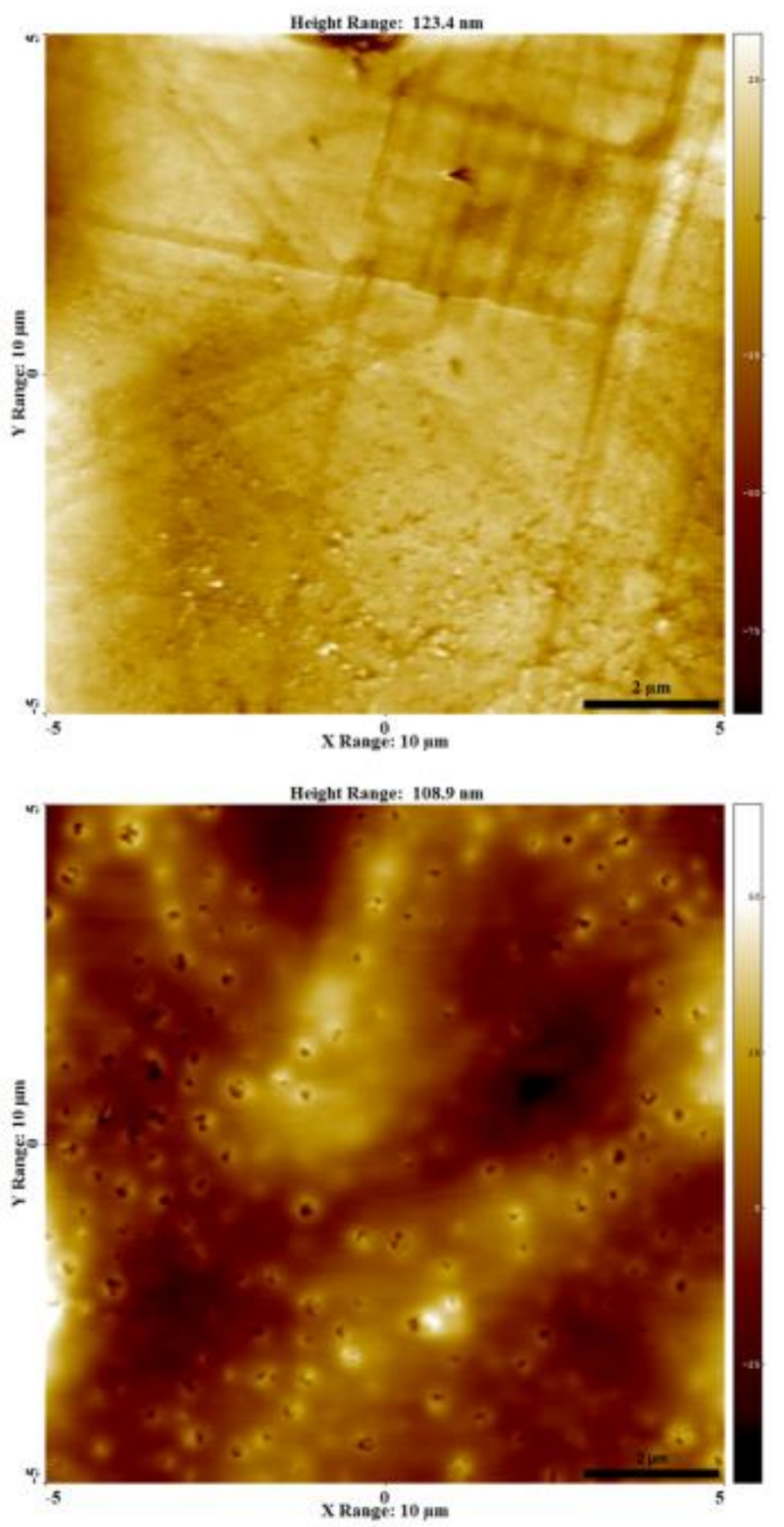
Figure 4. AFM images of PP/PP-g-MA (top) and as prepared PP-PEI-SMA-PEI (bottom).

$285109.6 \pm 2.4^{\circ}$ and $91.8 \pm 3.8^{\circ}$ and $\theta_{\mathrm{R}}$ values of $73.6 \pm 5.0^{\circ}$ and $40.2 \pm 0.8^{\circ}$, respectively). The

286 retention in hydrophobicity after introducing a coating with polar antimicrobial functional groups

287 (e.g. primary amines, $N$-halamine forming groups) was likely a result of the styrene subunits in 288 the SMA cross-linking polymer. Static contact angles of aqueous buffered solutions ( $\mathrm{pH}$ ranges

289 1-13) were acquired to determine surface $\mathrm{p} K_{\mathrm{a}}$ values and characterize net charge of the material 290 (Figure 5). Unlike what has been reported in prior works characterizing $\mathrm{p} K_{\mathrm{a}}$ of interfaces 291 containing amine groups [20, 44-46, 54], a sigmoidal trend was not observed. Indeed, $\theta_{\mathrm{S}}$ values 292 were constant across the entire range of $\mathrm{pH}$ values tested (Figure 5). In the cited works, an 293 increase in $\theta_{\mathrm{S}}$ has been reported in a sigmoidal fashion as $\mathrm{pH}$ increases, brought by the 294 deprotonation of the amine groups, and this functional group tends to exhibit the lower part of 295 the sigmoidal curve at low $\mathrm{pH}$ values $[44,45]$. It is possible that the introduction of both acid 296 and base groups (as well as nonpolar styrene units) in the reported coating introduces a chemical 297 heterogeneity [55] that effectively neutralizes the expected positive charge at neutral $\mathrm{pH}$ values. 298 Reducing the net positive charge (and therefore propensity for fouling) of an antimicrobial 299 polymer, while retaining antimicrobial character, is significant for its commercial adoption in 300 food and biomedical industries. 


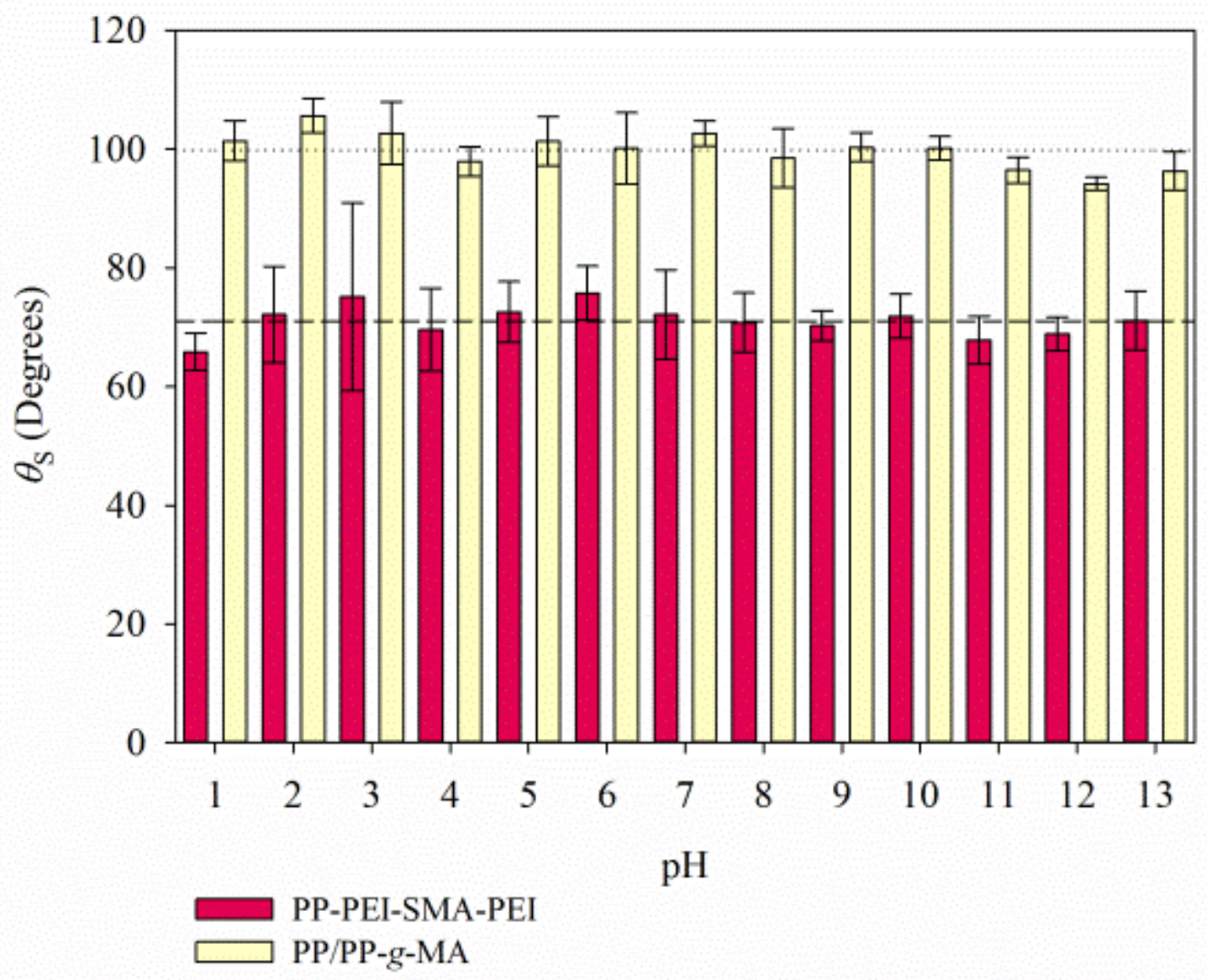

301

302 Figure 5. $\theta_{\mathrm{S}}$ values for the surface $\mathrm{p} K_{\mathrm{a}}$ determination (dotted and dashed lines are PP/PP- $g$-MA 303 and PP-PEI-SMA-PEI $\theta_{\mathrm{S}}$ average values, respectively, for the entire $\mathrm{pH}$ range tested).

\subsection{Antimicrobial evaluations}

305 The antimicrobial coating demonstrated antimicrobial efficacy in the entire range of organic

306 matter concentration tested. At the lowest organic loads (up to $500 \mathrm{ppm}$ horse serum) the

307 chlorinated PP-PEI-SMA-PEI imparted inactivation below the limit of detection of the assay,

308 providing $>99.99 \%$ reduction $(>4$ logarithmic cycles) in E. coli O157:H7 (Figure 6 and Table

309 S1). Even in its unchlorinated state, the cationic moieties present in the PP-PEI-SMA-PEI

310 enabled between $1.9(\sim 99.0 \%)$ and $3.2(\sim 99.9 \%)$ logarithmic cycles in reduction in the presence 
311 of up to $500 \mathrm{ppm}$ horse serum. At 5,000 ppm of horse serum, chlorinated and not chlorinated PP-

312 PEI-SMA-PEI exhibited a similar behavior, providing $>99 \%$ reduction $(>2$ logarithmic cycles,

$313 \sim 99.4 \%$ in its cationic form and $\sim 99.7 \%$ in its $N$-halamine form). Added bleach (positive

314 control to mimic the amount of chlorine given by chlorinated PP-PEI-SMA-PEI) was able to

315 inactivate E. coli $\mathrm{O} 157: \mathrm{H} 7$ under the limit of detection $\left(1 \log \left(\mathrm{CFU} \mathrm{mL} L^{-1}\right)\right)$ from 0 to $5,000 \mathrm{ppm}$

316 horse serum. At 50,000 ppm, in contrast to what was seen between 0 and 5,000 ppm,

317 unchlorinated PP-PEI-SMA-PEI exhibited higher antimicrobial efficacy ( $90 \%$ reduction) than its

318 chlorinated ( $N$-halamine) counterpart (between $75-80 \%$ reduction). The lower efficacy as

319 compared to the cationic form at 50,000 ppm horse serum could be explained from the necessary

320 diffusion of chlorine to turn into hypochlorous acid $(\mathrm{HClO})$ and provide an antimicrobial effect.

321 In addition, this phenomenon can be affected by factors like $\mathrm{pH}$ and the presence of organic

322 matter, which neutralizes the oxidative chlorine. Indeed, it has long been established that

323 chlorine sanitizers perform poorly in the presence of high organic loads $[13,15,56]$. These

324 results indicate that the mechanism of the reported coating's antimicrobial activity changes

325 depending on the matrix in which it is applied. Under conditions of no or low organic load,

326 chlorination of $\mathrm{N}$-halamine groups in the coating results in enhanced antimicrobial activity,

327 whereas at higher organic loads, the cationic moieties present in the PP-PEI-SMA-PEI dominate

328 over $N$-halamine groups in imparting antimicrobial efficacy. Nevertheless, retention of even

329 reduced antimicrobial efficacy of $N$-halamine derived antimicrobial materials in the presence of

330 high organic load is significant.

An important aspect to consider for the application of this type of antimicrobial coating in

332 the food and biomedical industries is the potential release of the antimicrobial compound, and an

333 assessment of its potential toxicity. $N$-halamine derived polymer coatings are believed to exert 
334 their antimicrobial efficacy either by direct oxidation of microorganisms or by dissociation from 335 the $N$-halamine moiety as hypochlorous acid ( $\mathrm{HClO})$ [15]. In the current study, the maximum 336 concentration of chlorine released from the coatings was $14.1 \pm 1.3 \mathrm{ppm}$ (based on the $\mathrm{N}$ 337 halamine quantification, which characterizes concentration of chlorine released into $1 \mathrm{ml}$ test 338 solution per $\mathrm{cm}^{2}$ of coated PP, Figure 3), which is substantially lower than the maximum 339 concentration $(200 \mathrm{ppm})$ of $\mathrm{NaClO}$ (bleach) allowed for surface disinfection [47]. In addition to 340 the lower amount necessary to impart an antimicrobial effect, no toxic effects should be expected 341 from this type of coating. When it comes from $N$-halamines, chlorine is believed to be released 342 and interact with its surroundings in a much slower rate than when it comes from bleach, 343 suggesting their enhanced stability compared to bleach [13, 21]. Further, $N$-halamine polymer 344 coatings have been suggested to be relatively safe for use in industry [16]. Nevertheless, 345 additional studies are needed which demonstrate that the reported coatings do not pose a 346 significant risk in terms of human or environmental toxicity.

347 Performance of antimicrobial materials whose mechanism is (in part) from cationic 348 functional groups is limited if the net positive charge results in fouling of matrix components 349 (e.g. proteins, lipids) or microorganisms. In addition to effectively blocking the antimicrobial 350 function of the material, such fouling conditions a surface for biofilm establishment. Materials 351 were therefore imaged by SEM after antimicrobial activity assays, under conditions of no and 352 high organic load ( 0 and 50,000 ppm horse serum), with and without chlorination. The SEM 353 images acquired after the antimicrobial evaluations confirm no evidence of bacterial adhesion 354 (Figure S1). 


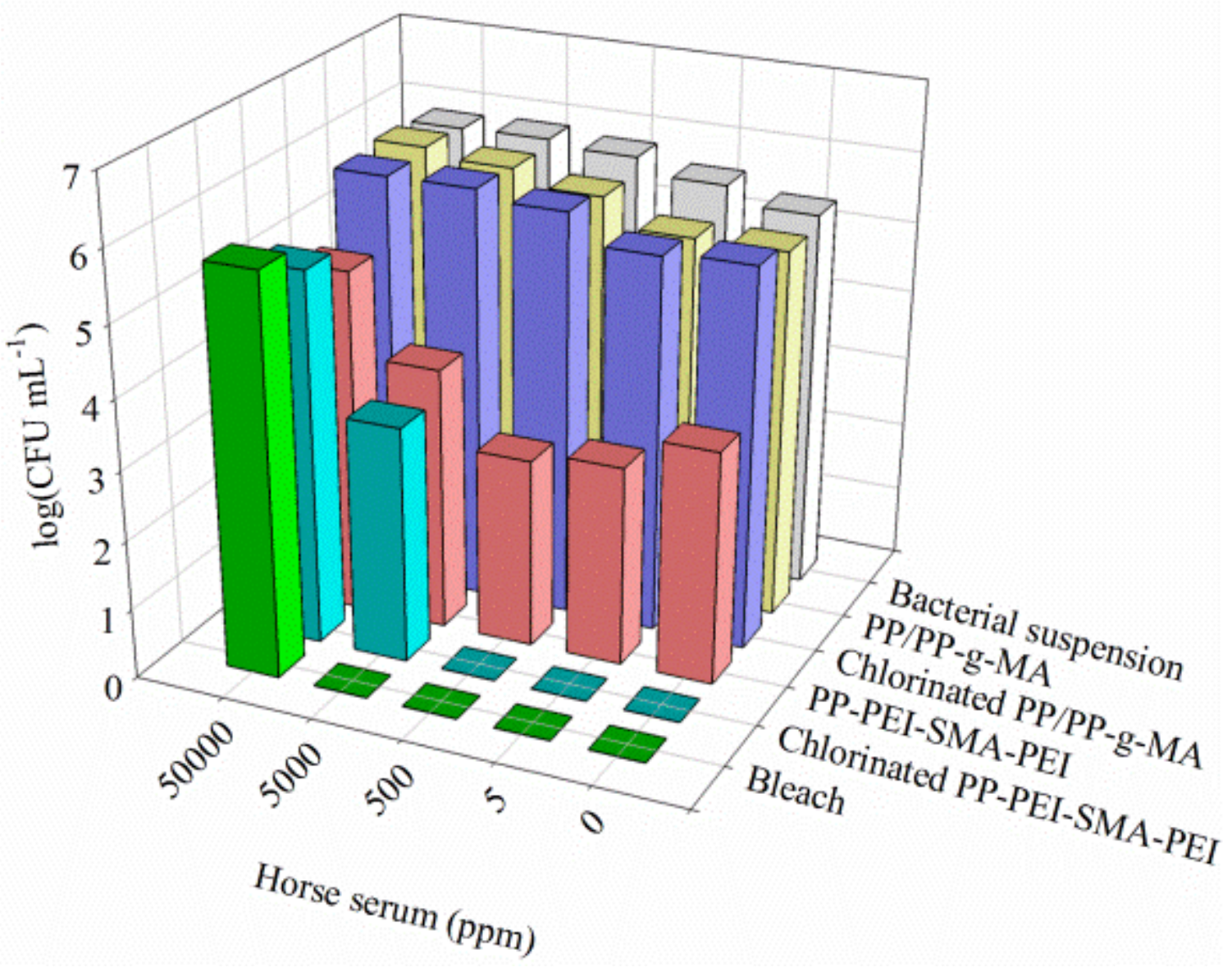

356 Figure 6. Antimicrobial evaluation (results are average values of at least 3 replicates; statistical significance and standard deviations can be found in Table S1).

\subsection{Self-healing evaluations}

360 Figure 7 shows the IR spectra of PP-PEI-SMA-PEI after exposure to $\mathrm{pH}$ extremes (top: acid,

361 bottom: alkaline) and subsequent self-healing by heating for $20 \mathrm{~min}$ at $140{ }^{\circ} \mathrm{C}$. The materials

362 exhibited excellent stability against acid degradation, as indicated by only minor changes in

363 chemistry after exposure to $5 \% \mathrm{HCl}$ or after subsequent self-healing. After exposure to acid,

364 there are subtle increases in absorbances corresponding to the $\mathrm{O}-\mathrm{H}$ vibration of carboxylic acids 
365 and the N-H bond in-place bend of secondary amines $\left(3400-3200 \mathrm{~cm}^{-1}\right.$ and $\sim 1550 \mathrm{~cm}^{-1}$, 366 respectively [52]), suggesting some hydrolysis of the imide ring found in the covalent bonds 367 between PEI and SMA. A decrease in the amine bend after heating at $140{ }^{\circ} \mathrm{C}$ for 20 min supports 368 the reformation of the imide bond, indicating the self-healing nature of the coating. The increase 369 at $\sim 1550 \mathrm{~cm}^{-1}$ is more pronounced after exposure to $4 \% \mathrm{NaOH}$ (Figure 7, bottom graph). This 370 band also decreases after self-healing at $140{ }^{\circ} \mathrm{C}$, suggesting regeneration of the imide rings, 371 which can also be confirmed from an increase in the absorbance at $\sim 1650 \mathrm{~cm}^{-1}$, characteristic of 372 the $\mathrm{C}=\mathrm{O}$ vibration of amides and imides [52]. XPS results support these observations (Figure 8).

373 Specifically, the increase in the deconvolution bands characteristic of the $\mathrm{C}-\mathrm{O}$ bond from the 374 high resolution $\mathrm{O} 1 \mathrm{~s}$ spectrum, and the decrease in the deconvolution band of $\mathrm{O}=\mathrm{C}-\mathrm{N}$ in $\mathrm{N} 1 \mathrm{~s}$, 375 followed by their restoration after $20 \mathrm{~min}$ at $140{ }^{\circ} \mathrm{C}$, is suggestive of self-healing after exposure 376 to acid degradation conditions. Exposure to alkaline degradation conditions, and subsequent self377 healing thermal treatment, resulted in more subtle changes in the high resolution O 1s XPS 378 spectrum, but similar behavior in the high resolution N 1s spectrum as observed in acid treated 379 materials (Figure 9). As with acid treated, self-healed materials, materials exposed to alkaline 380 degradation conditions restored characteristic deconvolution bands in N 1s and $\mathrm{O}$ 1s spectra after $38120 \mathrm{~min}$ at $140{ }^{\circ} \mathrm{C}$. Full statistical analysis of XPS results is reported in Table S2. It is worth 382 noting that thermal treatment of polymeric coatings containing chlorinated $\mathrm{N}$-halamines could 383 result in production of reactive species which may degrade the coatings. However, it is expected 384 that coatings needing regeneration would be in their unchlorinated state, either by the 385 consumption of chlorine during regular use or by incorporating a sodium thiosulfate 386 neutralization step prior to self-healing treatment. 
Surfaces were further imaged by SEM to characterize morphology after exposure to 388 acid/alkali degradation conditions and corresponding self-healing treatments (Figure S2). No 389 obvious changes were observed and coatings retained uniformity with no evidence of cracking or 390 delamination. Finally, no significant difference was found in the $N$-halamine content between 391 the as prepared PP-PEI-SMA-PEI coupons $\left(107.9 \pm 31.2 \mathrm{nmol} \mathrm{cm}^{-2}\right)$, the self-healed after 392 exposure to $5 \% \mathrm{HCl}\left(160.1 \pm 18.5 \mathrm{nmol} \mathrm{cm}^{-2}\right)$ and the self-healed after exposure to $4 \% \mathrm{NaOH}$ $393\left(145.0 \pm 9.1 \mathrm{nmol} \mathrm{cm}^{-2}\right)(P>0.05)$. Together with spectroscopy results, these data suggest that 394 the coatings would be robust against common cleaning and sanitization agents to which materials 395 used in food and biomedical industries are commonly exposed, and that acid and base 396 hydrolyzed imide bonds can be reformed by thermal treatment. Previous works have reported that higher molecular weight polymeric coatings harboring $398 N$-halamines exhibit substantially more stability than small molecule $N$-halamines. However, it is 399 not only the molecular weight but the functional groups contained in the $N$-halamine structures 400 that dictates stability. The presence of methyl groups can bring stability to the system by 401 providing an electron to the released chlorine in its oxidized form $\left(\mathrm{Cl}^{+}\right)$, which allows the $\mathrm{N}-\mathrm{Cl}$ 402 bond to be preserved. In contrast, the presence of carbonyl groups can have a detrimental effect 403 on the stability of the $\mathrm{N}-\mathrm{Cl}$ bond in the system as this chemical species is able to withdraw 404 electrons, contrary to methyl groups [13]. Amide groups are prone to hydrolysis upon exposure 405 to diluted bleach, which could result in breakdown of molecules and polymer backbones. Amine 406 groups show more stability, and may be more resistant to hydrolysis. If these two functional 407 groups are present within the same system harboring $N$-halamines, a substantial improvement in 408 stability can be obtained $[21,57]$. It is anticipated that the proximity of the coating to the PP/PP409 g-MA support and its methyl groups could be a source of stability for the $\mathrm{N}-\mathrm{Cl}$ bond. The imide 
410 ring closing from the curing step is also expected to provide stability to the system and to the

411 bonds between PEI and SMA, by diminishing the presence of amide groups (prone to exhibit 412 hydrolysis) [38, 58-59].
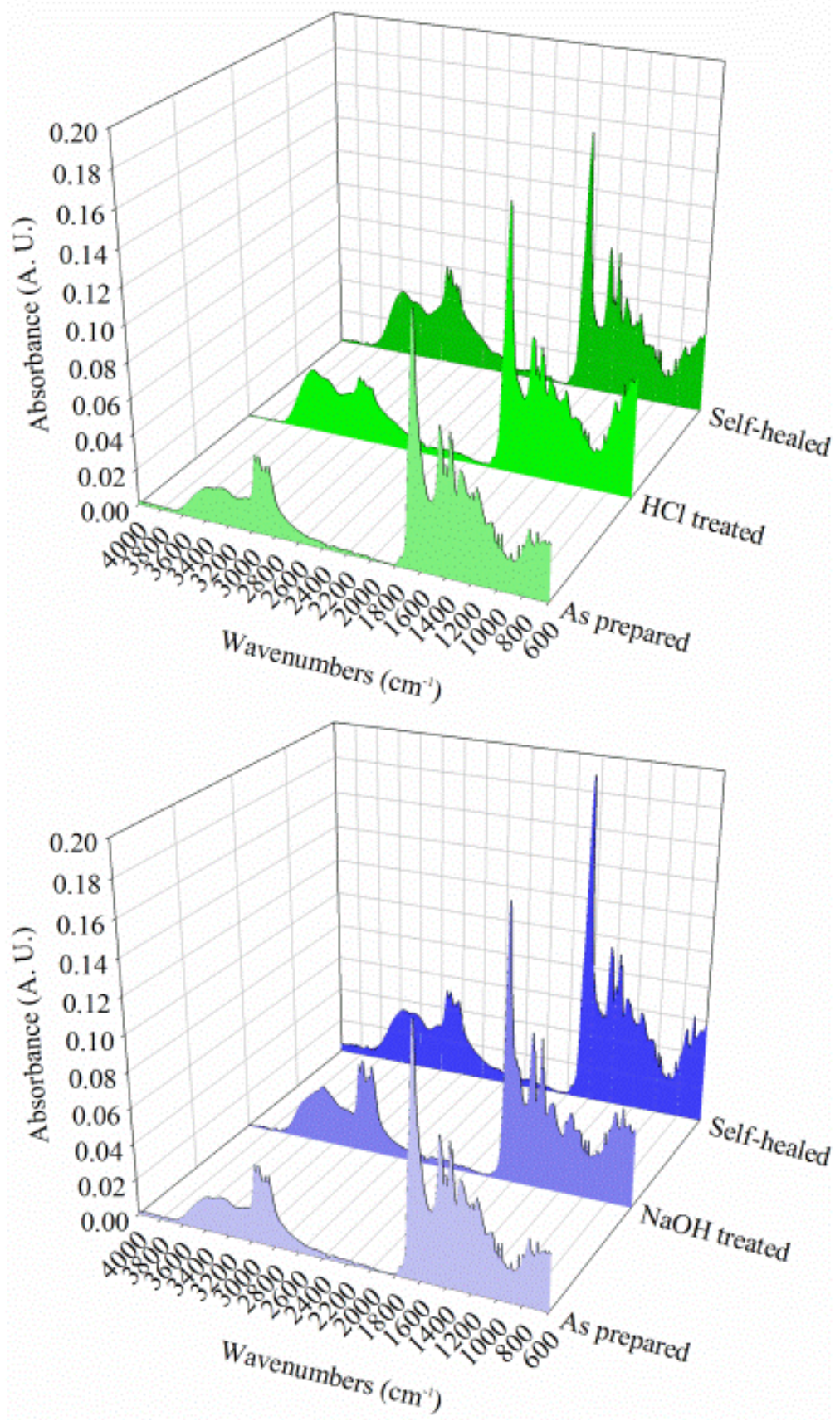

413

Figure 7. ATR-FTIR results of the self-healing evaluations. 

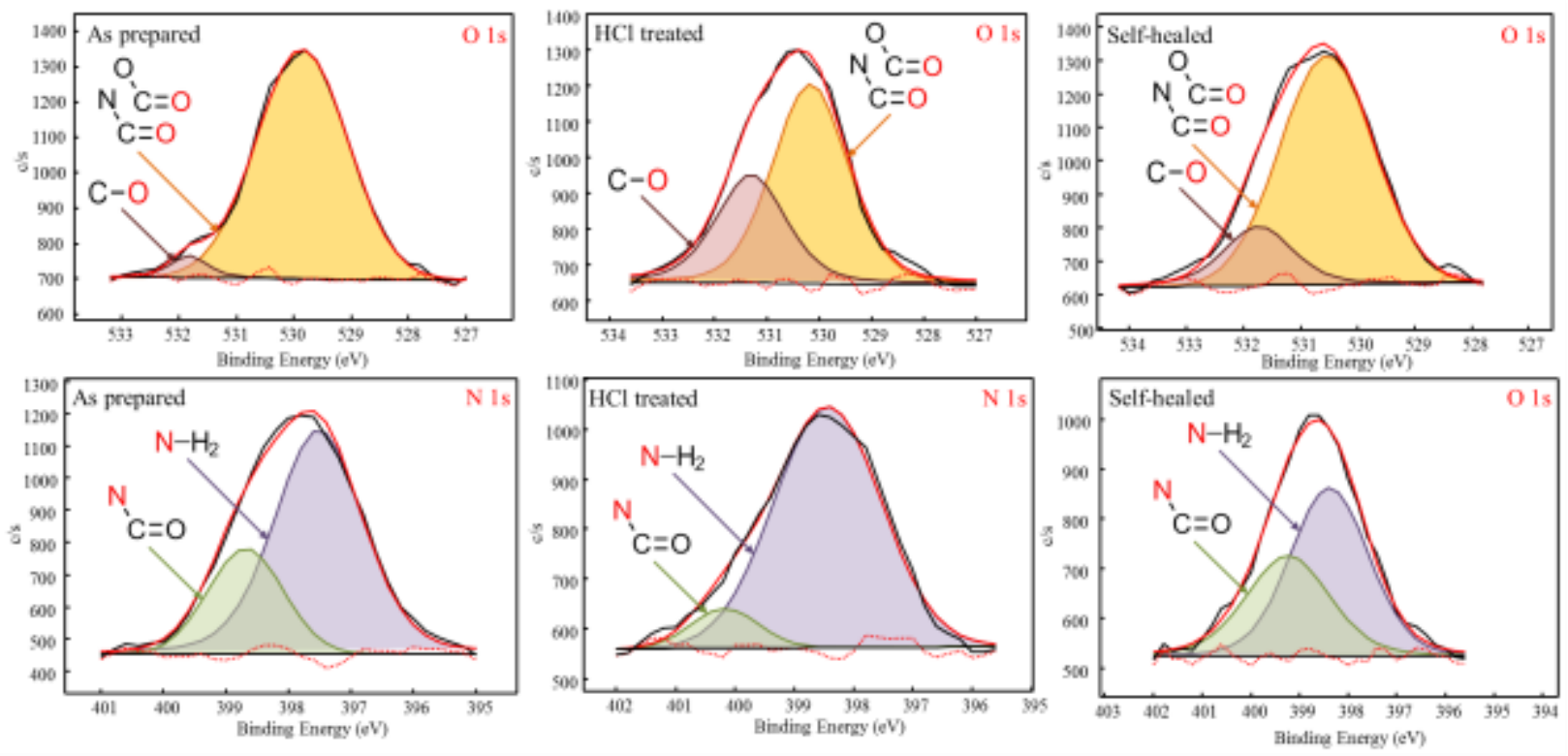

417

Figure 8. Self-healing evaluation with $5 \% \mathrm{HCl}$.
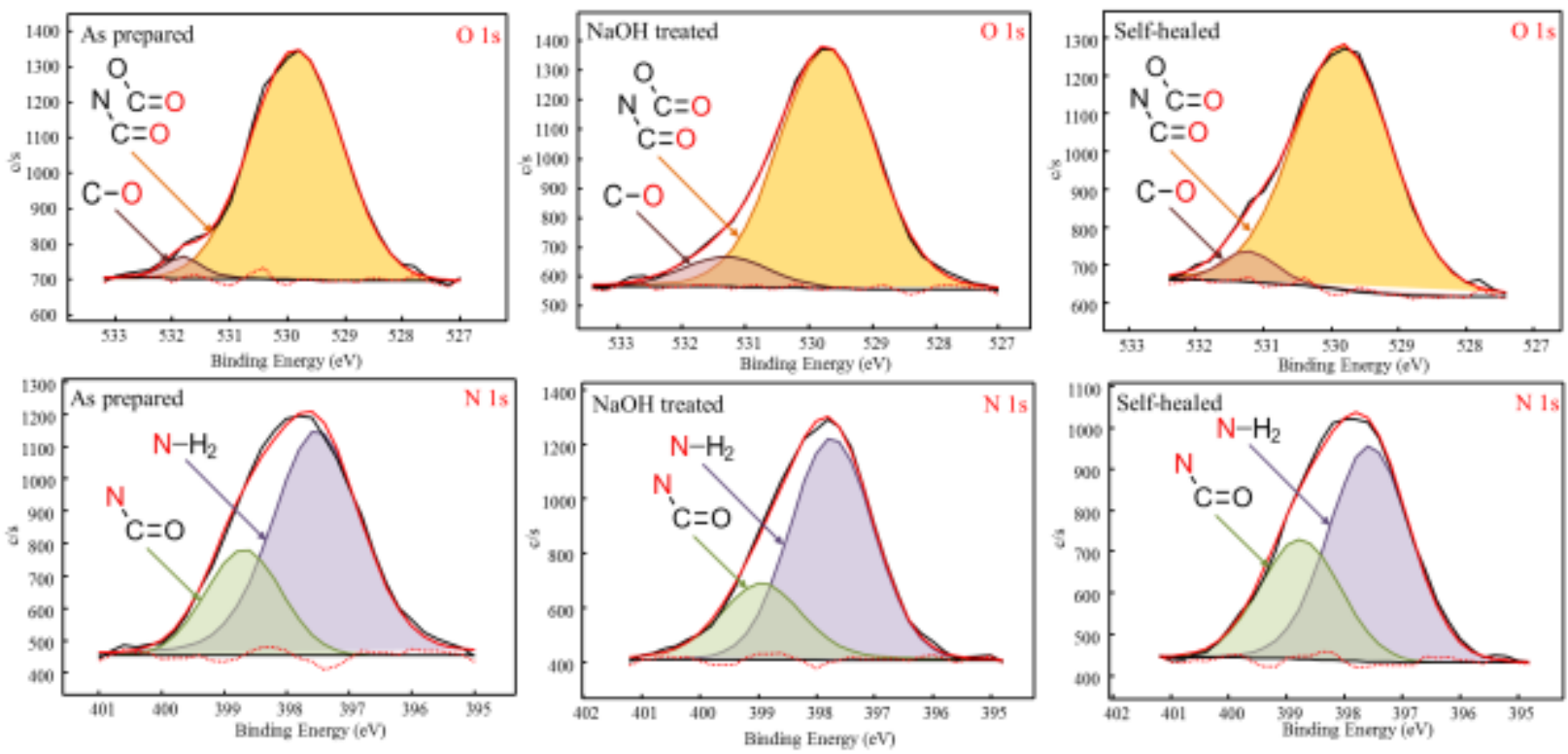

Figure 9. Self-healing evaluation with $4 \% \mathrm{NaOH}$. 
424 The antimicrobial material PP-PEI-SMA-PEI demonstrated intrinsic antimicrobial character

425 against $E$. coli $\mathrm{O} 157: \mathrm{H} 7$ both in its cationic form (giving up to $\sim 99.9 \%$ reduction), and an

426 enhanced antimicrobial effect in its $N$-halamine form ( $>99.99 \%$ reduction) under increasing

427 levels of organic matter (from 0 to $500 \mathrm{ppm}$ of horse serum). At $5000 \mathrm{ppm}$ of horse serum, both

428 antimicrobial modes of PP-PEI-SMA-PEI exhibited a similar biocidal effect (between $\sim 99.4 \%$

429 and $\sim 99.7 \%$ reduction). At the maximum level of organic matter tested (50000 ppm horse

430 serum), PP-PEI-SMA-PEI in its cationic form was more effective $(\sim 90 \%$ reduction $)$ than its $N$ -

431 halamine counterpart (between $\sim 75 \%$ and $\sim 80 \%$ reduction), and both modes showed significant

$432(P<0.05)$ reduction in microbial load as compared to the controls. The antimicrobial coating

433 was prepared through a scalable coat-cure process, resulting in a porous and hydrophobic

434 surface. Biocidal efficacy may be further improved (reducing contact time required for

435 inactivation and increasing log reduction values of microbial populations) by increasing the

436 number of SMA and PEI bilayers $[26,42,43]$. The coating application process can be made

437 more commercially translatable by use of spray deposition as has been previously reported [60,

438 61], as well as use of commercially available heat curing lamps. The antimicrobial coating

439 showed self-healing properties upon heating after exposure to acid and alkali degradation

440 conditions. Studies characterizing the stability of chlorinated $N$-halamines in the reported

441 coatings under conditions of intended use (e.g. dry, humid, and wetted conditions) are necessary

442 prior to commercial adoption. Indeed, stability of the $\mathrm{N}-\mathrm{Cl}$ bond in $\mathrm{N}$-halamine coatings can be

443 a challenge to their efficacy and such instability was (in part) a motivation for integrating both

444 N-halamine and cationic antimicrobial moieties into the reported coating. Further, in this work,

445 chlorine content of the chlorinated N-halamines was determined by subjecting materials to a 
446 rigorous rinse step in deionized water prior to chlorine quantification by DPD assay. This

447 rigorous rinse step was used to remove unbound chlorine and to allow decomposition of any less

448 stable $\mathrm{N}-\mathrm{Cl}$ bonds, so that highly unstable $\mathrm{N}$-halamines were not expected to be included in the

449 N-halamine quantification. Even though the stability of $N$-halamine coatings has been evaluated

450 under conditions of $\mathrm{pH}$ extremes, light exposure, continuous recharge of chlorine, etc.[18, 19, 21,

451 62], their performance in the presence of organic matter has not been demonstrated, probably due

452 to the well characterized neutralization of chlorine by organic matter, which limits the biocidal

453 efficacy of chlorine based sanitizers and $N$-halamine coatings alike [9]. Cationic antimicrobials

454 have been challenged against microorganisms in the presence of organic matter [31] but, in

455 contrast to $N$-halamines, their stability has not been widely evaluated $[9,20]$. The reported

456 hybrid antimicrobial coatings, with both cationic and $N$-halamine moieties, self-healing

457 character, intrinsic hydrophobicity, and efficacy even under conditions of increasing organic

458 load, may support reducing microbial cross-contamination in food and biomedical industries. 
460 Appendix A. A table with results from the antimicrobial evaluation, and a table with the results 461 from the XPS analysis after the self-healing evaluations, and SEM figures after the antimicrobial 462 and self-healing evaluations are included in Appendix A.

\section{Author Contributions}

464 The manuscript was written through contributions of all authors. All authors have given approval 465 to the final version of the manuscript. These authors contributed equally.

\section{Funding Sources}

467 This material is based upon work supported by the National Institute of Food and Agriculture, 468 U.S. Department of Agriculture under project number 2011-65210-20059.

\section{ACKNOWLEDGMENT}

471 The authors wish to thank Prof. Lynne A. McLandsborough for use of her facilities for the 472 antimicrobial evaluations; Prof. D. Julian McClements for the use of his Drop Shape Analyzer 473 DSA100; Prof. Thomas McCarthy and Jacob Hirsch for use of their Physical Electronics

474 Quantum 2000; Prof. Alan J. Lesser for use of his Brabender mixer; and Dr. Sekar T. 475 Dhanasekaran for training and assistance in the AFM analysis.

\section{ABBREVIATIONS}

477 PP, Polypropylene; PP-g-MA, Polypropylene-graft-maleic anhydride; PEI, branched 478 polyethyleneimine; SMA, styrene maleic anhydride copolymer; DI, deionized; HEPES, 4-(2479 hydroxyethyl)-1-piperazineethane-sulfonic acid; ATR-FTIR, Attenuated Total Reflectance 480 Fourier Transform Infrared Spectroscopy; XPS, X-Ray Photoelectron Spectroscopy; AFM, 
Atomic Force Microscopy; AO7, Acid Orange 7; DPD, N,N-diethyl-p-phenylenediamine; TSB,

Tryptic Soy Broth; TSA, Tryptic Soy Agar; SEM, Scanning Electron Microscopy; ASTM,

American Society for Testing and Materials.

484

485

486

487

488

489

490

491

492

493

494

495

496

497

498

499

500

501

502

503

504

505

506

507

508

509

510

511

\section{REFERENCES}

[1] Centers for Disease Control and Prevention (CDC), Vital Signs: Incidence and Trends of Infection with Pathogens Transmitted Commonly through Food--Foodborne Diseases Active Surveillance Network, 10 U.S. Sites, 1996-2010. MMWR. Morbidity and mortality weekly report. 60 (2011) 749-755.

[2] Magill, S. S.; Edwards, J. R.; Bamberg, W.; Beldavs, Z. G.; Dumyati, G.; Kainer, M. A.; Lynfield, R.; Maloney, M.; McAllister-Hollod, L.; Nadle, J.; Ray, S. M.; Thompson, D. L.; Wilson, L. E.; Fridkin, S. K. Multistate Point- Prevalence Survey of Health CareAssociated Infections. N. Engl. J. Med. 370 (2014) 1198-1208.

[3] Food and Drug Administration Report of the FDA Retail Food Program Database of Foodborne Illness Risk Factors. http://www.fda.gov/downloads/Food/GuidanceRegulation/UCM123546.pdf, 2000 (accessed 16.02.10).

[4] Van Houdt, R.; Michiels, C. W. Biofilm Formation and the Food Industry, a Focus on the Bacterial Outer Surface. J. Appl. Microbiol. 109 (2010) 1117-1131.

[5] Brooks, J. D.; Flint, S. H. Biofilms in the Food Industry: Problems and Potential Solutions. Int. J. Food Sci. Technol. 43 (2008) 2163-2176.

[6] Verran, J.; Airey, P.; Packer, A.; Whitehead, K. A. Microbial Retention on Open Food Contact Surfaces and Implications for Food Contamination. Adv. Appl. Microbiol. 64 (2008) 223-246.

[7] Moretro, T.; Langsrud, S. Effects of Materials Containing Antimicrobial Compounds on Food Hygiene. J. Food Prot. 74 (2011) 1200-1211.

[8] Ratner, B. D. Surface Modification of Polymers: Chemical, Biological and Surface Analytical Challenges. Biosens. Bioelectron. 10 (1995) 797-804.

[9] Bastarrachea, L. J.; Denis-Rohr, A.; Goddard, J. M. Antimicrobial Food Equipment Coatings: Applications and Challenges. Annu. Rev. Food Sci. Technol. 6 (2015) 97-118.

[10] Cutter, C. The Effectiveness of Triclosan-Incorporated Plastic Against Bacteria on Beef Surfaces. J. Food Prot. 62 (1999) 474-479. 
[11] Cowan, M.; Abshire, K.; Houk, S.; Evans, S. Antimicrobial Efficacy of a Silver-Zeolite Matrix Coating on Stainless Steel. J. Ind. Microbiol. Biotechnol. 30 (2003) 102-106.

[12] Goddard, J. M.; Hotchkiss, J. H. Rechargeable Antimicrobial Surface Modification of Polyethylene. J. Food Prot. 71 (2008) 2042-2047.

[13] Worley, S.; Williams, D. Halamine Water Disinfectants. Crit. Rev. Environ. Control. 18 (1988) $133-175$.

[14] Kovacic, P.; Lowery, M. K. Chemistry of N-Halamines. XII. Amination of Alkyl Halides with Trichloramine-Aluminum Chloride. J. Org. Chem. 34 (1969) 911-917.

[15] Williams, D.; Elder, E.; Worley, S. Is Free Halogen Necessary for Disinfection? Appl. Environ. Microbiol. 54 (1988) 2583-2585.

[16] Hui, F.; Debiemme-Chouvy, C. Antimicrobial N-Halamine Polymers and Coatings: A Review of their Synthesis, Characterization, and Applications. Biomacromolecules. 14 (2013) 585-601.

[17] Kenawy, E. R.; Worley, S. D.; Broughton, R. The Chemistry and Applications of Antimicrobial Polymers: A State-of-the-Art Review. Biomacromolecules. 8 (2007) 13591384.

[18] Cerkez, I.; Kocer, H. B.; Worley, S. D.; Broughton, R. M.; Huang, T. S. N-Halamine Biocidal Coatings Via a Layer-by-Layer Assembly Technique. Langmuir. 27 (2011) 40914097.

[19] Kocer, H. B.; Akdag, A.; Worley, S. D.; Acevedo, O.; Broughton, R. M.; Wu, Y. Mechanism of Photolytic Decomposition of N-Halamine Antimicrobial Siloxane Coatings. ACS Appl. Mater. Interfaces. 2 (2010) 2456-2464.

[20] Bastarrachea L.J., G. J. M. Antimicrobial Coatings with Dual Cationic and N-Halamine Character: Characterization and Biocidal Efficacy. J. Agric. Food Chem. 63 (2015) 42434251.

[21] Bastarrachea, L. J.; McLandsborough, L. A.; Peleg, M.; Goddard, J. M. Antimicrobial NHalamine Modified Polyethylene: Characterization, Biocidal Efficacy, Regeneration, and Stability. J. Food Sci. 79 (2014) E887-E897.

[22] Lichter, J. A.; Rubner, M. F. Polyelectrolyte Multilayers with Intrinsic Antimicrobial Functionality: The Importance of Mobile Polycations. Langmuir. 25 (2009) 7686-7694.

[23] Kugler, R.; Bouloussa, O.; Rondelez, F. Evidence of a Charge-Density Threshold for Optimum Efficiency of Biocidal Cationic Surfaces. Microbiology. 151 (2005) 1341-1348. 
[24] Fang, B.; Jiang, Y.; Rotello, V. M.; Nuesslein, K.; Santore, M. M. Easy Come Easy Go: Surfaces Containing Immobilized Nanoparticles Or Isolated Polycation Chains Facilitate Removal of Captured Staphylococcus aureus by Retarding Bacterial Bond Maturation. ACS Nano. 8 (2014) 1180-1190.

[25] Mansilla, A. Y.; Albertengo, L.; Rodriguez, M. S.; Debbaudt, A.; Zuniga, A.; Casalongue, C. A. Evidence on Antimicrobial Properties and Mode of Action of a Chitosan obtained from Crustacean Exoskeletons on Pseudomonas syringae pv. Tomato DC3000. Appl. Microbiol. Biotechnol. 97 (2013) 6957-6966.

[26] Xia, B.; Dong, C.; Lu, Y.; Rong, M.; Lv, Y.; Shi, J. Preparation and Characterization of Chemically-Crosslinked Polyethyleneimine Films on Hydroxylated Surfaces for Stable Bactericidal Coatings. Thin Solid Films 2011, 520, 1120-1124.

[27] Wang, B.; Navath, R. S.; Menjoge, A. R.; Balakrishnan, B.; Bellair, R.; Dai, H.; Romero, R.; Kannan, S.; Kannan, R. M. Inhibition of Bacterial Growth and Intramniotic Infection in a Guinea Pig Model of Chorioamnionitis using PAMAM Dendrimers. Int. J. Pharm. 395 (2010) 298-308.

[28] Murata, H.; Koepsel, R. R.; Matyjaszewski, K.; Russell, A. J. Permanent, Non-Leaching Antibacterial Surfaces - 2: How High Density Cationic Surfaces Kill Bacterial Cells. Biomaterials. 28 (2007) 4870-4879.

[29] Liu, Y.; Strauss, J.; Camesano, T. A. Adhesion Forces between Staphylococcus Epidermidis and Surfaces Bearing Self-Assembled Monolayers in the Presence of Model Proteins. Biomaterials. 29 (2008) 4374-4382.

[30] Rose, S. F.; Okere, S.; Hanlon, G. W.; Lloyd, A. W.; Lewis, A. L. Bacterial Adhesion to Phosphorylcholine-Based Polymers with Varying Cationic Charge and the Effect of Heparin Pre-Adsorption. J. Mater. Sci.: Mater. Med. 16 (2005) 1003-1015.

[31] Onnis-Hayden, A.; Hsu, B. B.; Klibanov, A. M.; Gu, A. Z. An Antimicrobial Polycationic Sand Filter for Water Disinfection. Water Sci. Technol. 63 (2011) 1997-2003.

[32] Li, L.; Pu, T.; Zhanel, G.; Zhao, N.; Ens, W.; Liu, S. New Biocide with both N-Chloramine and Quaternary Ammonium Moieties Exerts Enhanced Bactericidal Activity. Adv. Healthc. Mater. 1 (2012) 609-620.

[33] Liang, J.; Chen, Y.; Barnes, K.; Wu, R.; Worley, S. D.; Huang, T. S. N-Halamine/Quat Siloxane Copolymers for use in Biocidal Coatings. Biomaterials. 27 (2006) 2495-2501.

[34] Liu, Y.; Liu, Y.; Ren, X.; Huang, T. S. Antimicrobial Cotton Containing N-Halamine and Quaternary Ammonium Groups by Grafting Copolymerization. Appl. Surf. Sci. 296 (2014) 231-236. 
[35] Yang, Y.; Urban, M. W. Self-Healing Polymeric Materials. Chem. Soc. Rev. 42 (2013) 7446-7467.

[36] Blaiszik, B. J.; Kramer, S. L. B.; Olugebefola, S. C.; Moore, J. S.; Sottos, N. R.; White, S. R. Self-Healing Polymers and Composites. Ann. Rev. Mater. Res. 40 (2010) 179-211.

[37] Skorb, E. V.; Andreeva, D. V. Self-Healing Properties of Layer-by-Layer Assembled Multilayers. Polym. Int. 64 (2015) 713-723.

[38] Song, Z. Q.; Baker, W. E. Chemical-Reactions and Reactivity of Primary, Secondary, and Tertiary Diamines with Acid Functionalized Polymers. J. Polym. Sci. Pol. Chem. 30 (1992) 1589-1600.

[39] Hermanson, G. T. In Bioconjugate Techniques; Academic Press: Boston, MA, 2008; Vol. 381, pp 1202.

[40] Uchida, E.; Uyama, Y.; Ikada, Y. Sorption of Low-Molecular-Weight Anions into Thin Polycation Layers Grafted Onto a Film. Langmuir. 9 (1993) 1121-1124.

[41] American Society for Testing and Materials. Standard Test Methods of Sampling and Chemical Analysis of Chlorine-Containing Bleaches. D 2022 - 89. ASTM: Philadelphia, PA, USA, 2008.

[42] Bastarrachea, L. J.; Goddard, J. M. Development of Antimicrobial Stainless Steel Via Surface Modification with N-Halamines: Characterization of Surface Chemistry and NHalamine Chlorination. J. Appl. Polym. Sci. 127 (2013) 821-831.

[43] Bastarrachea, L. J.; Peleg, M.; McLandsborough, L. A.; Goddard, J. M. Inactivation ofListeria Monocytogeneson a Polyethylene Surface Modified by Layer-by-Layer Deposition of the Antimicrobial N-Halamine. J. Food Eng. 117 (2013) 52-58.

[44] Holmes-Farley, S.; Reamey, R.; McCarthy, T.; Deuth, J.; Whitesides, G. Acid-Base Behavior of Carboxylic-Acid Groups Covalently Attached at the Surface of Polyethylene the Usefulness of Contact-Angle in Following the Ionization of Surface Functionality. Langmuir. 1 (1985) 725-740.

[45] Holmes-Farley, S.; Bain, C.; Whitesides, G. Wetting of Functionalized Polyethylene Film having Ionizable Organic-Acids and Bases at the Polymer Water Interface - Relations between Functional-Group Polarity, Extent of Ionization, and Contact-Angle with Water. Langmuir. 4 (1988) 921-937.

[46] Van der Maaden, K.; Sliedregt, K.; Kros, A.; Jiskoot, W.; Bouwstra, J. Fluorescent Nanoparticle Adhesion Assay: A Novel Method for Surface $\mathrm{pK}_{\mathrm{a}}$ Determination of SelfAssembled Monolayers on Silicon Surfaces. Langmuir. 28 (2012) 3403-3411. 
[47] Rutala, W.; Weber, D. In Guideline for Disinfection and Sterilization in Healthcare Facilities, 2008; Centers for Disease Control (U.S.): Washington, DC, 2008; , pp 158.

[48] Djordjevic, D.; Wiedmann, M.; McLandsborough, L. Microtiter Plate Assay for Assessment of Listeria monocytogenes biofilm Formation. Appl. Environ. Microbiol. 68 (2002) 29502958.

[49] Bursik, A. In Condensate Polishing; Dorfner, K., Ed.; Ion Exchangers; De Gruyter: Berlin, New York, 1991; pp 791-831.

[50] Singh, R. In Membrane technology and engineering for water purification: application, systems design and operation; Butterworth-Heinemann: Oxford, UK, 2015; pp 452.

[51] American Society for Testing and Materials. Standard Practice for Evaluation of Chemical Resistance of Printed Inks and Coatings of Flexible Packaging Materials. F2250-03. ASTM: West Conshohocken, PA, USA, 2003.

[52] Smith, B. In Infrared spectral interpretation: a systematic approach; CRC Press: Boca Raton, FL, 1999; pp 265.

[53] Chevalier, E.; Chulia, D.; Pouget, C.; Viana, M. Fabrication of Porous Substrates: A Review of Processes using Pore Forming Agents in the Biomaterial Field. J. Pharm. Sci. 97 (2008) $1135-1154$.

[54] Vezenov, D.; Noy, A.; Rozsnyai, L.; Lieber, C. Force Titrations and Ionization State Sensitive Imaging of Functional Groups in Aqueous Solutions by Chemical Force Microscopy. J. Am. Chem. Soc. 119 (1997) 2006-2015.

[55] Miles, I. S. In Polymer interfaces; Miles, I. S., Rostami, S., Eds.; Multicomponent Polymer Systems; Longman Group UK Limited; John Wiley \& Sons, Inc.: New York, NY, USA, 1992; 17-62.

[56] Deborde, M.; von Gunten, U. Reactions of Chlorine with Inorganic and Organic Compounds during Water Treatment - Kinetics and Mechanisms: A Critical Review. Water Res. 42 (2008) 13-51.

[57] K. Tan, S.K. Obendorf, Fabrication and evaluation of electrospun nanofibrous antimicrobial nylon 6 membranes, J. Membr. Sci. 305 (2007) 287-298.

[58] N.P. Gule, O. Bshena, M. de Kwaadsteniet, T.E. Cloete, B. Klumperman, Immobilized Furanone Derivatives as Inhibitors for Adhesion of Bacteria on Modified Poly(styrene-comaleic anhydride), Biomacromolecules. 13 (2012) 3138-3150.

[59] H. Liu, Z. Yao, K. Cao, B. Li, Kinetic Analysis of the Imidization of Poly(styrene-co-maleic anhydride) with Aniline in the Melt, J Appl Polym Sci. 116 (2010) 2951-2957. 
646 [60] Denis-Rohr, A.; Bastarrachea, LJ; Goddard, JM. Antimicrobial efficacy of N-halamine 647 coatings prepared via dip and spray layer-by-layer deposition. Food and Bioprod. Process. $648 \quad 96(2015)$ 12-19.

649 [61] Izquierdo A, Ono S, Voegel J, Schaaf P, Decher G. Dipping versus spraying: Exploring the 650 deposition conditions for speeding up layer-by-layer assembly. Langmuir. 21 (2005) 7558$651 \quad 7567$.

652 [62] Sun, Y. Y.; Sun, G. Novel Regenerable N-Halamine Polymeric Biocides. III. Grafting 653 Hydantoin-Containing Monomers Onto Synthetic Fabrics. J. Appl. Polym. Sci. 81 (2001) $654 \quad 1517-1525$.

655

656 